\title{
Dietary supplementation effects of Chlorella vulgaris on performances, oxidative stress status and antioxidant enzymes activities of prepubertal New Zealand White rabbits
}

\author{
A. B. Sikiru ${ }^{1,2}$, A. Arangasamy² ${ }^{*}$, I. C. Alemede ${ }^{1}$, S. S. A. Egena ${ }^{1}$ and R. Bhatta ${ }^{2}$
}

\begin{abstract}
Background: Chlorella vulgaris (CV) is a natural source of functional antioxidants capable of protecting against oxidative stress; its dietary supplementation in animals can serve as a way of improving animals' performance and productive output; on this background, the microalgae was supplemented to growing New Zealand white rabbits and its effects on performances and oxidative stress status were evaluated.

Method: Thirty-five (35) 6-week-old New Zealand White rabbits $(935.48 \pm 5.92 \mathrm{~g})$ were divided into five groups $(n=$ 7 per group) in a completely randomized design experiment; rabbits in control groups were fed only commercial rabbits feed, while rabbits in treatment groups were supplemented with 200, 300, 400, and $500 \mathrm{mg}$ Chlorella vulgaris biomass per kilogram of the body weight along with commercial rabbits feed daily. Feed intake and body weight changes were recorded daily and weekly; at the end of the study, blood was collected and subjected to chemical assays for evaluation of serum oxidative stress markers and antioxidant activities.

Results: Dietary supplementation of the microalgae significantly increased the rabbits' growth weights $(p<0.01)$ without significant increase or reduction in feed intakes $(p<0.56)$, but significantly enhanced feed to gain ratio. The microalgae supplementation significantly protected the rabbits against oxidative stress damages through the reduction of malondialdehyde concentrations $(p<0.001)$ and increased total antioxidant capacity $(p<0.003)$. It also led to higher superoxide dismutase activity $(p<0.001)$, increased catalase activity $(p<0.003)$, and higher concentration of reduced glutathione $(p<0.001)$.

Conclusion: It was concluded from outcomes of both performance and biochemical analysis of the rabbits that daily supplementation of Chlorella vulgaris between 200 and $500 \mathrm{mg}$ per kilogram of the body weight in prepubertal rabbits significantly improved performances in forms of higher weight gains and enhanced feed utilization; it also protected against oxidative stress damages hence it was recommended as dietary antioxidant supplement for growing prepubertal rabbits.
\end{abstract}

Keywords: Chlorella vulgaris, Oxidative stress, Antioxidant enzymes and Performance characteristics

\footnotetext{
* Correspondence: arangasamyars@gmail.com

${ }^{2}$ Reproductive Physiology Laboratory, ICAR-National Institute of Animal

Nutrition and Physiology, Bangalore, India

Full list of author information is available at the end of the article
} 


\section{Background}

Oxidative stress is a limiting biochemical mechanism endogenously associated with electron leakage from electron transport chain during spontaneous oxidative phosphorylation in the mitochondria; closely associated with energy-demanding physiological activities such as reproductive development (Aitken and Roman 2008). Oxidative stress was reported to affect reproductive development in mice model; a condition mediated by hepatic dysfunction in the biosynthesis of cholesterol required for production of steroid hormones including the sex hormones progesterone, estrogen, and testosterone hence compromising endocrine system (Jin et al. 2011). Therefore, the need for oxidative stress protection in prepubertal rabbit is important strategy for ensuring optimum reproductive development in rabbits meant for commercial breeding and meat production.

Dietary antioxidant supplementation is a suggested way out for mitigation of oxidative stress since it is a process of imbalance between prooxidants and antioxidants endogenously; therefore, additional external antioxidants supply is capable of contributing to direct and or indirect quenching of free radicals as a way of complementing the primary antioxidant enzymes activities (Wu et al. 2005). Some cultivated and wild plants, oilseeds, micro, and macroalgae are potent sources of these antioxidant protection principles. Antioxidant enzyme activities and accumulation of oxidative stress products such as malondialdehyde, carbonylated proteins, and 4hydroxy-2-nonenal are generally used for evaluation of oxidative stress severity status in animals and or man as well as determining efficacy of dietary antioxidant supplementation. Therefore, in this study Chlorella vulgaris capacity was investigated because the microalga was reported to contain carotenoids, polyphenols, vitamins, and minerals with antioxidant functional properties.

\section{Materials and methods}

\section{Animals and their management}

Thirty-five (35) female 6-week-old New Zealand white rabbits obtained from Biogen Biotechnology (Pvt.) Ltd., India, was used for this study; the animals were divided into five groups ( $n=7$ per group) in a completely randomized design experiment; they were intensively housed in cages installed with feeders and automatic drinkers. Commercial pelletized rabbit feed (Krishna Valley Agrotech LLP; India) and water were provided ad libitum to all the rabbits, but in addition, rabbits in treatment groups were supplemented with 200, 300, 400, and $500 \mathrm{mg}$ Chlorella vulgaris biomass per kilogram of the body weight daily; the nutrient composition of the basal feed is presented in Table 1. The experiment took place at Experimental Livestock Unit (ELU) of ICARNational Institute of Animal Nutrition and Physiology,
Table 1 Chemical and nutritional composition of commercial basal feed fed to the rabbits

\begin{tabular}{lll}
\hline Parameters & Amount & Unit \\
\hline Dry matter & 90.89 & $\%$ dry matter \\
Crude protein & 18.55 & $\%$ \\
Total ash & 7.90 & $\%$ \\
Metabolizable energy & 2700 & $\mathrm{kcal} / \mathrm{kg}$ \\
Crude fiber & 9.73 & $\%$ \\
Ether extract & 2.99 & $\%$ \\
\hline
\end{tabular}

Source: Laboratory analysis

Bengaluru, India. Animal experimentation protocol approval was obtained from the Institutional Animal Ethics Committee (IAEC) of the institute.

\section{Lipid peroxidation assay}

Lipid peroxidation assay protocol involving the determination of malondialdehyde (MDA) formation in the serum of the experimental animals was used in this study. Frozen serum earlier obtained from each animal stored at $-22{ }^{\circ} \mathrm{C}$ were allowed to thaw overnight at $4{ }^{\circ} \mathrm{C}$ before used for the analysis. Briefly, $200 \mu \mathrm{L}$ serum sample added with a complex of sodium- $n$-dodecyl (8.1\%), acetic acid (20\%), and thiobarbituric acid $(0.8 \%)$ then boiled at $95{ }^{\circ} \mathrm{C}$ in water bath for $60 \mathrm{~min}$ (Ohkawa et al. 1979). The complexes after boiling were cooled in tap water and the flocculent precipitates were removed by centrifugation at $3500 \mathrm{rpm}$ for $15 \mathrm{~min}$ (REMI Laboratory Instruments, India). Absorbance reading of the supernatant was measured at $532 \mathrm{~nm}$ against blank which contains all the reagents without the serum samples using UV/Vis spectrophotometer (Biochrom Libra S32, UK). The concentration of malondialdehyde of the samples was calculated using its molar extinction coefficient.

\section{Total antioxidant capacities assay}

Total antioxidant assay based redox activities of iron (III) to iron (II) at low $\mathrm{pH}$ was used in this study; a working chemical assay containing $25 \mathrm{~mL}$ sodium acetate buffer (300 mM, pH 3.6), $2.5 \mathrm{~mL}$ of $10 \mathrm{mM}$ 2,4,6-Tri-(2 pyridyl)$\mathrm{s}$-trizine prepared in $40 \mathrm{mM} \mathrm{HCl}$, and $2.5 \mathrm{~mL}$ Ferric chloride (20 mM prepared in distilled water) was prepared as described by Benzie and Strain (1996). Then, the reaction mixture comprising $50 \mu \mathrm{L}$ of each sample and $200 \mu \mathrm{L}$ of the working solution was incubated for $30 \mathrm{~min}$ at $37{ }^{\circ} \mathrm{C}$ (Labnet Inc., USA) after which the absorbance was measured at $493 \mathrm{~nm}$ using microplate reader. Ascorbic acid was used as standard for calculating antioxidant power associated with color changes and reduction of $\mathrm{Fe}^{3+}$ to $\mathrm{Fe}^{2+}$; total antioxidant concentration was expressed as micromole per milliliter of each sample. 


\section{Antioxidant enzyme activities}

Antioxidant enzymes including superoxide dismutase, catalase, glutathione, and reductase were determined; catalase activities in $\mathrm{U} / \mathrm{mL}$ were determined using quantity of hydrogen peroxide $\mathrm{H}_{2} \mathrm{O}_{2}$ degraded by catalase per minute in the serum (Goth 1991; Guvvala et al. 2017). Twenty microliters of serum sample from each animal in triplicates were added with $880 \mu$ l phosphate buffer $(\mathrm{pH}$ 7.0) and $100 \mu \mathrm{L} \mathrm{H}_{2} \mathrm{O}_{2}$ then mix properly after which absorbance reading was taking at $240 \mathrm{~nm}$ using UV/Vis spectrophotometer (Biochrom Libra S32, UK); reduction in absorbance reading against blank containing only the phosphate buffer and $\mathrm{H}_{2} \mathrm{O}_{2}$ for 3 min per sample was recorded and used for calculation of the catalase activities.

Superoxide dismutase capacity was determined on principle involving autooxidation of pyrogallol in the presence of DEPTA (diethylenetriaminepentaacetic acid) at the pH 8.5 by $50 \%$; a principle established and verified by Marklund and Marklund (1974); in this study, the protocol as modified by Guvvala et al. (2017) was adopted. Briefly, there was the kinetic measurement of changes in reaction mixture which contained $950 \mu \mathrm{L}$ of Tris cacodylate buffer, $50 \mu \mathrm{L}$ serum sample, and $10 \mu \mathrm{L}$ pyrogallol solution prepared in $10 \mathrm{mM} \mathrm{HCl}$ at $420 \mathrm{~nm}$. Absorbance changes of the reaction mixture measured against blank containing the reagents without serum sample for $3 \mathrm{~min}$ observed every $30 \mathrm{~s}$ was recorded and used for calculation of the enzyme activities expressed as $\mathrm{U} / \mathrm{mL}$ of serum.

Glutathione activity was evaluated based on glutathione reductase activities using a chemical assay protocol of Carlberg and Mannervik (1975). The reaction mixture of each test sample contained potassium phosphate buffer $(0.2 \mathrm{M}), 20 \mathrm{mM}$ glutathione substrate solution (GSSG), $2 \mathrm{mM} \beta-\mathrm{NADPH}$ prepared in Tris- $\mathrm{HCl}$, and the $50 \mu \mathrm{L}$ of serum sample. In a 5 -min reaction at absorbance of $340 \mathrm{~nm}$ changes at every $30 \mathrm{~s}$ recorded were used to quantify amount of reduced glutathione formed from NADP from reduction of GSSG in a reaction catalyzed by glutathione reductase (Mateen et al. 2016).

\section{Results}

Obtained data were subjected to a one-way analysis of variance (ANOVA) in SPSS version 20.0 (IBM Corporation, USA). Significant differences among the means were determined at $p<0.05$ while means separation was done using the Duncan test in the software post hoc tools, and results are presented as mean \pm SEM for each of the parameters. There was no significant difference in the initial body weights of the rabbits; mean initial body weight was $935.48 \pm 5.92 \mathrm{~g}(p<0.08)$, while minimum and maximum initial body weights were 824.00 and 994.00 g, respectively. However, there was significant difference in final bodyweight of the rabbits; mean final body weight was $2092.03 \pm 20.74 \mathrm{~g}(p<0.01)$, while minimum and maximum final body weights of the rabbits were 1691.80 and $2440 \mathrm{~g}$, respectively. The rabbits in the treatment groups have significantly higher final body weight compared with control (Table 2).

Furthermore, there was no significant difference in feed intake, but the control group has highest feed intake; mean feed intake was $5902.84 \pm 116.66 \mathrm{~g}(p<$ 0.56 ), while minimum and maximum feed intakes were 1801.35 and $6532.40 \mathrm{~g}$, respectively. However, there was a significant difference in the rabbits' weight gain; mean weight gain was $1156.56 \pm 22.54 \mathrm{~g}(p<0.003)$, while minimum and maximum weight gains were 776.80 and 1535.80 g, respectively. There was also significant difference in feed conversion ratio; mean feed conversion ratio was $5.2 \pm 0.01(p<0.003)$. Although there was no difference in feed intakes rabbits in treatment groups have higher weight gains and better feed conversion ratios compared with control group (Fig. 1).

There was also a significant difference in the oxidative stress status of the rabbits as revealed by concentrations of the malondialdehyde and total antioxidant capacity of the serum. Mean malondialdehyde concentration was $11.62 \pm 2.03 \mathrm{nmol} / \mathrm{mL}(p<0.001)$, while minimum and maximum concentrations of malondialdehyde were 4.52 and $38.06 \mathrm{nmol} / \mathrm{mL}$, respectively. Similarly, there was significant difference in total antioxidant capacities of the rabbits' serum; mean antioxidant capacity was 10.00 $\pm 2.24 \mu \mathrm{mol} / \mathrm{mL}(p<0.003)$, while minimum and maximum antioxidant capacities were 10.32 and $51.65 \mu \mathrm{mol} /$ $\mathrm{mL}$, respectively. There was higher level of oxidative stress in the control group compared with treatment groups as revealed in the levels of lipid peroxidation marker and antioxidant capacities; as the microalgae biomass increases, there was reduction in lipid peroxidation, while total antioxidant capacity increases (Fig. 2).

In addition, there were significant differences in activities of antioxidant enzymes of the rabbit's serum; superoxide dismutase enzyme activity was $79.42 \pm 5.47 \mathrm{U} / \mathrm{mL}$ $(p<0.001)$ while minimum and maximum activities were 28.67 and $110.08 \mathrm{U} / \mathrm{mL}$, respectively. There was also a significant difference in activities of catalase; mean activity was $28.88 \pm 3.38 \mathrm{U} / \mathrm{mL}(p<0.003)$ while minimum and maximum were 8.26 and $60.55 \mathrm{U} / \mathrm{mL}$, respectively. There was also a significant difference in glutathione enzymes; mean concentration of reduced glutathione formed was $32.80 \pm 2.04 \mu \mathrm{mol} / \mathrm{mL}(p<0.001)$, while minimum and maximum were 11.90 and $35.37 \mu \mathrm{mol} / \mathrm{mL}$, respectively. These results also indicated that antioxidant activities were higher in the treatment groups compared with control (Table 3).

\section{Discussion}

Oxidative stress negatively affects growth performance, nutrients absorption, and efficiency of feeds utilization 
Table 2 Effect of Chlorella vulgaris supplementation on performances of the rabbits

\begin{tabular}{llllllll}
\hline Parameters & Control & T1 & T2 & T3 & T4 & SEM & $p$ value \\
\hline Initial weight $(\mathrm{g})$ & 957.50 & 920.77 & 925.75 & 953.87 & 919.50 & 5.92 & 0.08 \\
Final weight $(\mathrm{g})$ & $1960.85^{\mathrm{b}}$ & $2143.72^{\mathrm{a}}$ & $2080.28^{\mathrm{a}}$ & $2110.90^{\mathrm{a}}$ & $2092.03^{\mathrm{a}}$ & 20.74 & 0.01 \\
Weight gain (g) & $1003.35^{\mathrm{b}}$ & $1222.95^{\mathrm{a}}$ & $1154.52^{\mathrm{a}}$ & $1157.02^{\mathrm{a}}$ & $1244.92^{\mathrm{a}}$ & 22.54 & 0.003 \\
Feed intakes (g) & 6084.36 & 5708.25 & 6069.12 & 6048.34 & 5604.14 & 116.66 & 0.56 \\
Feed conversion ratio & $6.12^{\mathrm{b}}$ & $4.82^{\mathrm{a}}$ & $5.27^{\mathrm{a}}$ & $5.24^{\mathrm{a}}$ & $4.52^{\mathrm{a}}$ & 0.14 & 0.003 \\
\hline
\end{tabular}

Means with different superscript letters along the rows are significantly different $(p<0.05)$ for each of the parameters measured. Control-no supplementation, T1-group supplemented with $200 \mathrm{mg}$ Chlorella vulgaris biomass, T2-group supplemented with 300 mg Chlorella vulgaris biomass, T3-group supplemented with $400 \mathrm{mg}$ Chlorella vulgaris biomass, and T4-group supplemented with $500 \mathrm{mg}$ Chlorella vulgaris biomass

in animals; it is a biochemical phenomenon capable of limiting performances and also suppresses immune function thereby compromising animal performance. Lipid peroxidation is identified as major mechanism through which oxidative stress compromise performance because it is a biological mechanism capable of reducing antioxidant protective system and reduced absorptive capacity of feeds nutrients (Yuan et al. 2007; Kassahn et al. 2009). Oxidative stress scenario is a complex phenomenon because it is almost inevitable is growing and producing animals; therefore, supplementation of antioxidants for its management as demonstrated in this study is required. Supplementation of microalgae Chlorella vulgaris in this study led to improved antioxidant enzyme activities in the treatment groups compared with control which corresponded with reduced oxidative stress as indicated by concentration of malondialdehyde formation in the treatment groups compared with control.

The supplementation of the experimental diets irrespective of the quantities per kilogram of the body weight significantly prevented the formation of malondialdehyde
(MDA) which is an indication that the supplementation prevented lipid peroxidation. Prevention of lipid peroxidation contributed to enhanced feed utilization which was why there were better feed conversion ratio and weight gain in the treatment groups compared with control. The improvement in efficiency of feed utilization and weight gain supported previous reports which indicated that the microalgal is a growth promoter.

This was reported according to Yan et al. (2012) who supplemented Chlorella vulgaris to growing pigs, and it was discovered that the microalga positively influenced weight gain in supplemented groups compared with control. Bioactive compounds including S-nucleotide adenosyl peptide complex, polysaccharides, and phenolic compounds present in abundance in the microalga could be responsible for the growth promotion (Kay and Barton 1991). In addition to direct effects of these compounds in growth promotion, increased antioxidant protection which is a determining factor of immune regulation could be responsible for the growth promotion as recorded because according to earlier studies on the microalgae; its supplementation

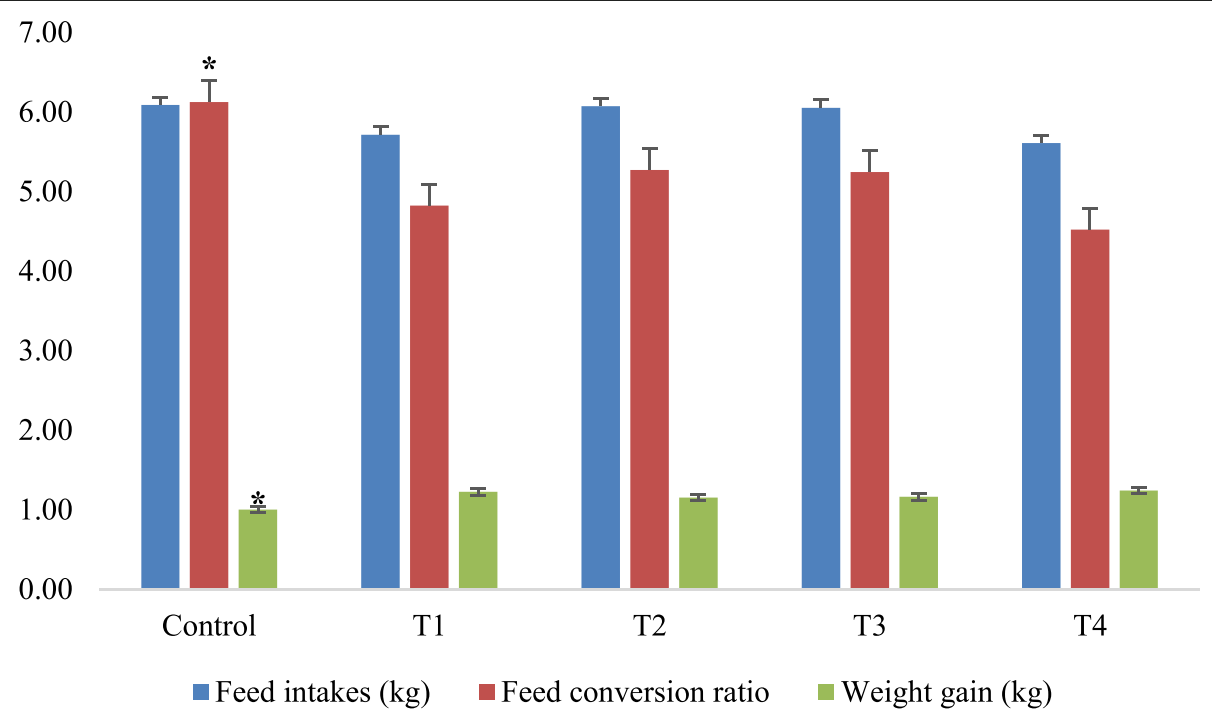

Fig. 1 Comparative effect of Chlorella vulgaris on feed use efficiency of the rabbits ( ${ }^{*} p<0.05$ ). Control—no supplementation, $\mathrm{T} 1$-group supplemented with $200 \mathrm{mg}$ Chlorella vulgaris biomass, T2-group supplemented with $300 \mathrm{mg}$ Chlorella vulgaris biomass, T3-group supplemented with $400 \mathrm{mg}$ Chlorella vulgaris biomass, and T4-group supplemented with $500 \mathrm{mg}$ Chlorella vulgaris biomass 


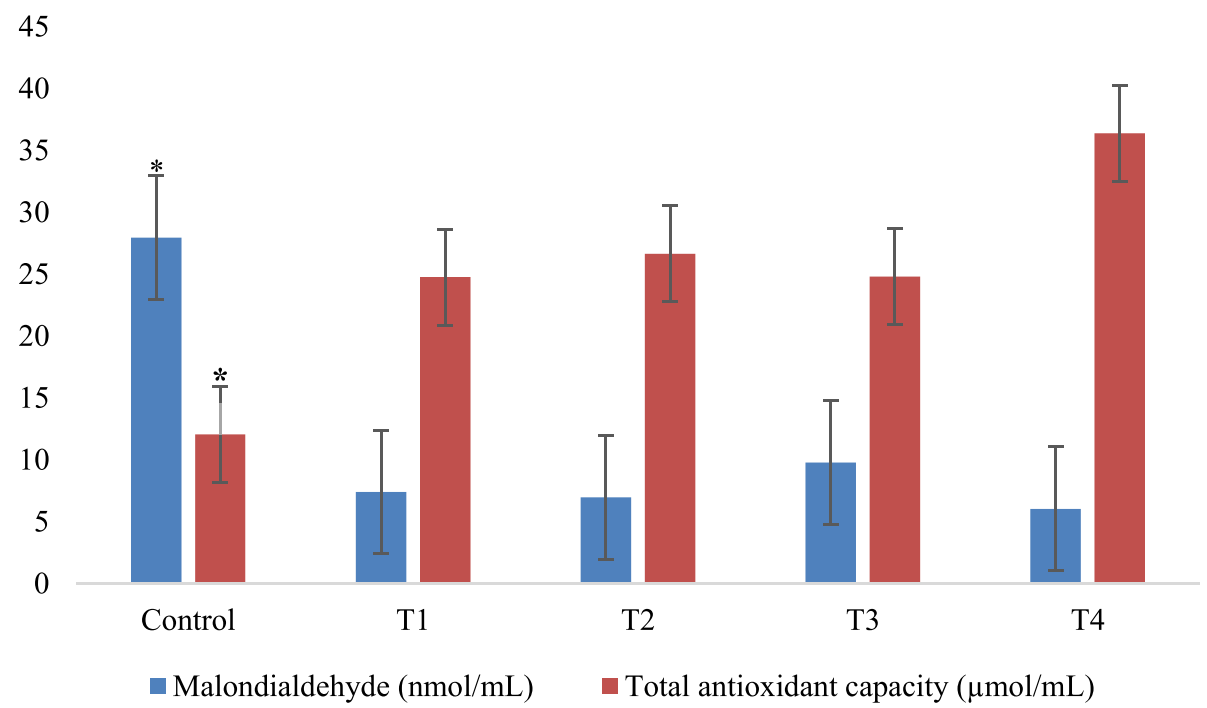

Fig. 2 Comparative effect of Chlorella vulgaris on lipid peroxidation and total antioxidant capacity of the rabbits $\left({ }^{*} p<0.05\right)$. Control -no supplementation, T1-group supplemented with $200 \mathrm{mg}$ Chlorella vulgaris biomass, T2 - group supplemented with $300 \mathrm{mg}$ Chlorella vulgaris biomass, T3-group supplemented with $400 \mathrm{mg}$ Chlorella vulgaris biomass, and T4_group supplemented with 500 mg Chlorella vulgaris biomass

increases concentration of probiotics in the intestinal tracts of animals, hence it leads to optimally utilization of absorbed nutrients intake and enhanced immunity (Janczyk et al. 2009).

In addition to these nutrition-related performance mechanisms, the microalgal was also reported with capacity for suppression of pathogenic bacteria in animals (Rania and Hala 2008). Juxtaposing these with outcomes of this study as regards the enhanced feed utilization, it can be concluded that the supplementation improved efficiency of feed intake utilization and there is growthpromoting principles in the microalgae, rather than bulk feeding of the algae; its supplementations at minimal of $200 \mathrm{mg}$ and optimum of $500 \mathrm{mg}$ per kilogram BW of rabbits at pre-pubertal stage can improve productivity.

In agreement with these observations, a study exploring supplementation effects of Spirulina-similar microalgae like Chlorella vulgaris by Heidarpour et al. (2011) also reported that supplementation of microalgae rather bulk feeding contributed to the growth rate in Holstein's calves and the authors suggested exploration of bioactive compounds in algae as functional nutrients for livestock productivity improvement. Furthermore, Chlorella vulgaris was identified as a natural growth promoter with excellent potential for accelerating growth rates in animals (Grinstead et al. 2000).

Similarly, in agreement with this present study, An et al. (2016), also reported that supplementation of dried Chlorella vulgaris powder not only significantly increased growth rates, but also increase final weight gain in broilers chicken compared with control unsupplemented group. The agreement between this report and the outcomes of this study indicated that absorptive efficiency of feed significantly improved in the rabbit which is also a caeca fermenter like chicken. Therefore, it is justified to state that microalgae Chlorella vulgaris is suitable natural source of growth promotion, immune-boosting, tissue rebuilding, and antioxidant protection in animals (Guzmán et al. 2003). These are demonstrated in this present study via improved antioxidant which is a functional effect of the microalgae, and it is in agreement with earlier reports in application of the microalgae. This study also showed that

Table 3 Effect of Chlorella vulgaris supplementation on serum oxidative stress status of the rabbits

\begin{tabular}{llllllll}
\hline Parameters & Control & T1 & T2 & T3 & T4 & SEM & $p$ value \\
\hline Malondialdehyde $(\mathrm{nmol} / \mathrm{mL})$ & $27.95^{\mathrm{a}}$ & $7.39^{\mathrm{b}}$ & $6.96^{\mathrm{b}}$ & $9.78^{\mathrm{b}}$ & $6.02^{\mathrm{b}}$ & 2.03 & 0.001 \\
Total antioxidant $(\mu \mathrm{mol} / \mathrm{mL})$ & $12.04^{\mathrm{a}}$ & $24.75^{\mathrm{b}}$ & $26.64^{\mathrm{bc}}$ & $24.78^{\mathrm{b}}$ & $36.38^{\mathrm{c}}$ & 2.24 & 0.003 \\
Catalase activity $(\mathrm{U} / \mathrm{mL})$ & $11.05^{\mathrm{a}}$ & $32.45^{\mathrm{b}}$ & $27.01^{\mathrm{b}}$ & $25.39^{\mathrm{b}}$ & $48.50^{\mathrm{c}}$ & 3.38 & 0.001 \\
Superoxide dismutase $(\mathrm{U} / \mathrm{mL})$ & $33.66^{\mathrm{a}}$ & $84.21^{\mathrm{bc}}$ & $77.28^{\mathrm{b}}$ & $88.63^{\mathrm{bc}}$ & $98.31^{\mathrm{c}}$ & 5.48 & 0.001 \\
Reduced glutathione $(\mu \mathrm{mol} / \mathrm{mL})$ & $21.06^{\mathrm{a}}$ & $39.82^{\mathrm{b}}$ & $30.74^{\mathrm{b}}$ & $36.48^{\mathrm{b}}$ & $36.04^{\mathrm{b}}$ & 2.04 & 0.010 \\
\hline
\end{tabular}

Means with different superscript letters along the rows are significantly different $(p<0.05)$ for each of the parameters measured. Control-no supplementation, T1—group supplemented with 200 mg Chlorella vulgaris biomass, T2_group supplemented with 300 mg Chlorella vulgaris biomass, T3-group supplemented with $400 \mathrm{mg}$ Chlorella vulgaris biomass, and T4-group supplemented with $500 \mathrm{mg}$ Chlorella vulgaris biomass 
supplementation of microalgal Chlorella vulgaris significantly suppressed generation of malondialdehyde in the treatment groups with corresponding elevated antioxidant enzyme activities. This is an indication that reproductive development and growth of the rabbit is a source of stress because since the animals were at prepubertal stage, their rigorous growing and development of reproductive system are source of oxidative stress (Agarwal et al. 2012).

It is evident that the growth and development of the reproductive system cause oxidative stress damages because absence of exogenous antioxidants supplementation in the control groups could be the reason for oxidative stress increase as result of reduced antioxidant enzymes, reduced total antioxidant capacities and higher concentration of oxidative stress marker malondialdehyde. This submission agreed with reports of increasing lipid peroxidation effect is reproductive development at prepubertal stage usually associated with decreased antioxidant enzyme activities because severe state of lipid peroxidation process is a major indicator of oxidative stress damage at prepubertal period (Kolesnikova et al. 2015).

Similarly, in a chemical-induced oxidative stress damages in prepubertal rat model, higher concentration of malondialdehyde with corresponding lower antioxidant enzyme activities as well as reproductive dysfunction including alterations in serum steroid hormone levels, disruptions of spermatogenesis, and loss of fertility (Cattani et al. 2013). In prepubertal male rabbits, lipid peroxidation was also reported to correspond with reduced antioxidant enzyme activities as well as causes negative effects on spermatogenesis reduced concertation (García-Tomás et al. 2010). However, in this study, it was demonstrated that even in an un-induced condition, there is a natural possibility of oxidative stress complications in actively growing rabbits at prepubertal stage due to free radical generation and a risk factor steroidal maturation and development of reproductive tissues (Fujii et al. 2005).

Earlier studies exploring Chlorella vulgaris as a source of protein for animals concluded with some shortcomings such as lack of significant differences in growth, digestibility, and high cost of feeding because of the expensiveness of the microalgae. Therefore, as solution and alternative route of utilization, this present study agreed with exploitation of functional health and physiological properties of the microalgal for promotion of animal production and health (Azizzat et al. 2010). Beyond amelioration of stress-associated growth and performance, supplementation of Chlorella vulgaris could contribute to improved physiological functions of the brain and hypothalamus axis, thereby leading to improved reproduction (Queiroz et al. 2016); supplementation of Chlorella vulgaris was also reported to protect against chemical cadmium toxicity via its detoxification in rat model (Kim et al. 2009; Elsheikh et al. 2018); it was also reported for testicular protection against lead toxicity in Nile tilapia according to reports of Zahran and Risha (2014).

\section{Conclusions}

The microalga was also reported for improvement of digestive tract health in piglets according to reports of Furbeyre et al. (2018) which could be the reasons why the rabbit supplemented had higher growth rate and better feed utilization because of the microalgae effects on the microbiome, digestive enzymatic activities, and nutrient absorption. Building on these health and physiological benefits, this present study filled the knowledge gap left in previous studies with Chlorella vulgaris which by focusing on minimal and optimum amount of the microalga required for attenuation of oxidative stress for improved performances. Upon these findings, study finally submit that Chlorella vulgaris biomass supplementation as tested in this study in prepubertal rabbits at minimal of $200 \mathrm{mg}$ and optimal of $500 \mathrm{mg}$ per kilogram body weight are capable of attenuating oxidative stress via prevention of malondialdehyde generation, increase total antioxidant capacity, and improve activities of primary endogenous antioxidant system all leading to improved production performances of rabbits.

\section{Abbreviations}

ANOVA: Analysis of variance; CCSTDS: Centre for Co-operation in Science \& Technology among Developing Societies; CV: Chlorella vulgaris;

DBT: Department of Biotechnology; DEPTA: Diethylenetriaminepentaacetic acid; ELU: Experimental Livestock Unit; HCl: Hydrochloric acid; IAEC: Institutional Animal Ethics Committee; IBM: International Business Machines Corporation; ICAR: Indian Council for Agricultural Research; LLP: Limited Liability Private Company; MDA: Malondialdehyde;

NIANP: National Institute of Animal Nutrition and Physiology, Bengaluru, India; PVT: Private; SEM: Standard error of means; SPSS: Statistical Package for the Social Sciences; TWAS: The World Academy of Sciences; UK: United Kingdom; USA: United States of America; UVNis: Ultraviolet-visible spectrophotometry; $\beta N A D P H: \beta$-Nicotinamide adenine dinucleotide 2'phosphate

\section{Acknowledgements}

Special thanks to The World Academy of Sciences (TWAS), Italy; Department of Biotechnology (DBT), Government of India; for joint award of doctoral fellowship to Sikiru A.B at ICAR-NIANP, Bangalore, where this study was conducted. We are grateful to authorities and management of the Federal University of Technology, Minna, Nigeria; the Director of ICAR-National Institute of Animal Nutrition and Physiology, Bangalore, India, for supporting this research and providing enabling environment for studies. We are also greatful to Centre for Co-operation in Science \& Technology among Developing Societies_CCSTDS (formerly CICS), Chennai, India, for coordination of fellowship under which this study was conducted. Special appreciation to Dr. Raghavendra B.S. (Research Associate), Reproductive Physiology Laboratory; ICAR-NIANP, Bangalore, India; for his insights and corrections of the manuscript draft.

\section{Authors' contributions}

$S A B$ did design the research and executed the field works, laboratory analysis, data analysis, and draft the manuscript. AA supervised the research, defended the research protocols, and edited the manuscript. AIC and ESSA validated the research experimental design and corrected the manuscript. BR 
corrected and edited the manuscript. All authors read and approved the final manuscript.

\section{Funding}

This project was funded by Department of Biotechnology, Government of India; The World Academy of Sciences (TWAS), Italy; and ICAR-National Institute of Animal Nutrition and Physiology, Bangalore, India, in a PhD Fellowship awarded to Sikiru A.B. on project titled "Influence of Chlorella vulgaris diets on reproductive performances and oxidative stress status at physiological reproductive stages in New Zealand White rabbits" (DBT-TWAS Postgraduate Fellowship-2017).

\section{Availability of data and materials}

Not applicable for this study.

\section{Ethics approval}

Approval of animal experimentation protocol in this study was secured from the Institutional Animal Ethics Committee (IAEC) of ICAR-National Institute of Animal Nutrition and Physiology, Bangalore, India, and Committee for the Purpose of Control and Supervision of Experiments on Animals (CPCSEA), India.

\section{Consent for publication}

Not applicable for this study

\section{Competing interests}

The authors declare that they have no competing interests.

\section{Author details}

${ }^{1}$ Department of Animal Production, Federal University of Technology, Minna, Nigeria. ${ }^{2}$ Reproductive Physiology Laboratory, ICAR-National Institute of Animal Nutrition and Physiology, Bangalore, India.

\section{Received: 20 June 2019 Accepted: 15 October 2019}

\section{Published online: 27 November 2019}

\section{References}

Agarwal A, Aponte-Mellado A, Premkumar BJ, Shaman A, Gupta S (2012) The effects of oxidative stress on female reproduction: a review. Reprod Biol Endocrinol 10(1):49

Aitken RJ, Roman SD (2008) Antioxidant systems and oxidative stress in the testes. Oxid Med Cell Longev 1(1):15-24

An BK, Kim KE, Jeon JY, Lee KW (2016) Effect of dried Chlorella vulgaris and Chlorella growth factor on growth performance, meat qualities and humoral immune responses in broiler chickens. Springerplus 5(1):718

Azizzat O, Yap SW, Sopiah H, Madiha MM, Hazreen M, Shailah A, Anum MY (2010) Modulation of oxidative stress by Chlorella vulgaris in streptozotocin (STZ) induced diabetic Spraque-Dawley rats. Adv Med Sci 55(2):281-288

Benzie IF, Strain JJ (1996) The ferric reducing ability of plasma (FRAP) as a measure of "antioxidant power": the FRAP assay. Anal Biochem 239(1):70-76

Carlberg INCER, Mannervik BENGT (1975) Purification and characterization of the flavoenzyme glutathione reductase from rat liver. J Biol Chem 250(14):5475-5480

Cattani D, Heinz CR, Pierozan P, Zanatta L, Benedetti EP, Wilhelm DF, Zamoner A (2013) Roundup disrupts male reproductive functions by triggering calciummediated cell death in rat testis and Sertoli cells. Free Radic Biol Med 65: 335-346

Kolesnikova LI, Darenskaya MA, Semenova NV, Grebenkina LV, Suturina LV, Dolgikh MI, Gnusina SV (2015) Lipid peroxidation and antioxidant protection in girls with type 1 diabetes mellitus during reproductive system development. Medicina 51(2):107-111

Elsheikh SM, Galal AA, Fadil RM (2018) Hepatoprotective impact of Chlorella vulgaris powder on deltamethrin intoxicated rats. Zag Vet J 46(1):17-24

Fujii J, luchi Y, Okada F (2005) Fundamental roles of reactive oxygen species and protective mechanisms in the female reproductive system. Reprod Biol Endocrinol 3(1):43-53

Furbeyre H, van Milgen J, Mener T, Gloaguen M, Labussière E (2018) Effects of oral supplementation with Spirulina and Chlorella on growth and digestive health in piglets around weaning. Animal:1-10
García-Tomás M, Sánchez J, Piles M, Mitjavila MT (2010) Line and birth season effects on plasma testosterone and oxidative stress parameters in testis of maturing rabbits. Anim Reprod Sci 117(3-4):314-321

Goth $L$ (1991) A simple method for determination of serum catalase activity and revision of reference range. Clin Chim Acta 196(2-3):143-151

Grinstead GS, Tokach MD, Dritz SS, Goodband RD, Nelssen JL (2000) Effects of Spirulina platensis on growth performance of weanling pigs. An Feed Sci Technol 83(3-4):237-247

Guvvala PR, Ravindra JP, Rajani CV, Sivaram M, Selvaraju S (2017) Protective role of epigallocatechin-3-gallate on arsenic induced testicular toxicity in Swiss albino mice. Biomed Pharmacother 96:685-694

Guzmán S, Gato A, Lamela M, Freire-Garabal M, Calleja JM (2003) Anti-inflammatory and immunomodulatory activities of polysaccharide from Chlorellastigmatophora and Phaeodactylumtricornutum. Phytother Res 17:665-670

Heidarpour A, Fourouz AD, Eghbalsaied S (2011) Effects of Spirulina platensis on performance, digestibility and serum biochemical parameters of Holstein calves. Afr J Agric Res 6(22):5061-5065

Janczyk P, Halle B, Souffrant WB (2009) Microbial community composition of the crop and ceca contents of laying hens fed diets supplemented with Chlorella vulgaris. Poult Sci 88(11):2324-2332

Jin Y, Zheng S, Pu Y, Shu L, Sun L, Liu W, Fu Z (2011) Cypermethrin has the potential to induce hepatic oxidative stress, DNA damage and apoptosis in adult zebra fish (Danio rerio). Chemosphere 82(3):398-404

Kassahn KS, Crozier RH, Pörtner HO, Caley MJ (2009) Animal performance and stress: responses and tolerance limits at different levels of biological organisation. Biol Rev 84(2):277-292

Kay RA, Barton LL (1991) Microalgae as food and supplement. Crit Rev Food Sci Nutr 30(6):555-573

Kim YJ, Kwon S, Kim MK (2009) Effect of Chlorella vulgaris intake on cadmium detoxification in rats fed cadmium. Nutr Res Pract 3(2):89-94

Marklund S, Marklund G (1974) Involvement of the superoxide anion radical in the autoxidation of pyrogallol and a convenient assay for superoxide dismutase. Eur J Biochem 47(3):469-474

Mateen S, Moin S, Khan AQ, Zafar A, Fatima N (2016) Increased reactive oxygen species formation and oxidative stress in rheumatoid arthritis. PloS One 11(4): e0152925

Ohkawa H, Ohishi N, Yagi K (1979) Assay for lipid peroxides in animal tissues by thiobarbituric acid reaction. Anal Biochem 95(2):351-358

Queiroz JS, Blasco IM, Gagliano H, Daviu N, Román AG, Belda X, Armario A (2016) Chlorella vulgaris reduces the impact of stress on hypothalamic-pituitaryadrenal axis and brain c-fos expression. Psychoneuroendocrinology 65:1-8

Rania MA, Hala MT (2008) Antibacterial and antifungal activity of cyanobacteria and green microalgae. Evaluation of medium components by placketburman design for antimicrobial activity of Spirulina platensis. Global J Biotechnol Biochem 3(1):22-31

Wu LC, Ho JAA, Shieh MC, Lu IW (2005) Antioxidant and antiproliferative activities of Spirulina and Chlorella water extracts. J Agric Food Chem 53(10):4207-4212

Yan L, Lin SU, Kim IH (2012) Effect of fermented Chlorella supplementation on growth performance, nutrient digestibility, blood characteristics, faecal microbial and faecal noxious gas content in growing pigs. Asian Austr J An Sci 25(12):1742-1747

Yuan SB, Chen DW, Zhang KY, Yu B (2007) Effects of oxidative stress on growth performance, nutrient digestibilities and activities of antioxidative enzymes of weanling pigs. Asian Austr J An Sci 20(10):1600-1605

Zahran E, Risha E (2014) Modulatory role of dietary Chlorella vulgaris powder against arsenic-induced immunotoxicity and oxidative stress in Nile tilapia (Oreochromis niloticus). Fish Shellfish Immunol 41(2):654-662

\section{Publisher's Note}

Springer Nature remains neutral with regard to jurisdictional claims in published maps and institutional affiliations. 